\title{
Spirometric Standards for Healthy Children Aged 6-15 Years in a School of Dhaka City, Bangladesh
}

\author{
JU MAZUMDER ${ }^{1}, \mathrm{SAHMED}^{2}, \mathrm{AH}^{\mathrm{MOLLAH}}{ }^{3}, \mathrm{ARML} \mathrm{KABIR}^{4}, \mathrm{~N} \mathrm{NAHAR}^{5}$
}

\begin{abstract}
Background: Prevalence of Asthma in children is about 7\% in Bangladesh but Spirometric value of children is not available.

Objective: The study was conducted to find out the spirometric value of normal school going children and to compare the values with those of other countries.

Methodology: Sprirometric evaluation of normal school going children was done by computerized spirometer (Ponygraphic of COSMED srl-Italy) in a school of Dhaka city during the period of February 2002 to July 2002. Nine hundred twenty seven healthy children aged 6-15 years were selected for the study. Outcome variable were the forced vital capacity ( $F V C)$, forced expiratory volume in first second $\left(F E V_{1}\right)$, peak expiratory flow (PEF), the ratio of FEV ${ }_{1}$ to $F V C$ and forced expiratory flow (FEF) between $25 \%$ \& $75 \%$ of vital capacity $\left(F E F_{25 \% \& 75 \%}\right)$. The pulmonary function data was separated by sex and categorized on the basis of height, weight, age and body surface area. The mean and standard deviation were calculated for every such variable. The results (FVC) of present study was compared with those of other countries (India, Nigeria, British and America).

Results: The lung function variables showed a linear positive correlation with height, weight, age and body surface area (independent variables). Strong correlation was found between lung function values and independent variables. Height showed the maximum correlation in comparison with other variable. Forced vital capacity (FVC) and $F E V_{1}$ showed a spurt after the height of $150 \mathrm{~cm}$. Regression equations for lung function values were determined for boys and girls considering height as independent variable. Boys showed higher values for lung functions than those of girls. Lung function values of these studied children are nearly similar to Indian children and significantly lower than Nigerian, British (UK) and American (USA) peers.
\end{abstract}

Conclusion: Spirometric values of our children are very much comparable with those of regional children (India) but values are lower than those of African (Nigeria), European (British) and American (USA) children.

Recommendation: Further study should be done with larger sample size to have our own national data and to fill up the standard spirometric values for the children of our country.

Key words: Spirometric standards, healthy children.

\section{Introduction}

Asthma is the most common chronic inflammatory disease in children and is a major global health problem $^{1-3}$. Prevalence of asthma in children is $7 \%$ in Bangladesh and is increasing day by day in our

1. Assistant Professor of Paediatrics, ICMH, Matuail, Dhaka

2. Assistant Professor of Paediatrics, Sylhet MAG Osmani Medical College, Sylhet

3. Professor and Head of the Department of Paediatrics, Dhaka Medical College, Dhaka

4. Professor of Paediatrics, ICMH, Matuail, Dhaka

5. Professor of Paediatrics, BIRDEM, Dhaka

Correspondence: Dr. Md Jashim Uddin Mazumder country and also globally ${ }^{1,4-9}$. Pulmonary function test of various types are utilized clinically and epidemiologically to measure the functional status of lungs in order to assess the disease ${ }^{10,11}$. Though they do not provide a specific diagnosis, but we can understand the physiology, course and progress of the respiratory diseases, assess the severity and help in the management of number of respiratory diseases ${ }^{11}$. Spirometry is the method of choice for evaluation of pulmonary function. It is indicated in all the children with clinical diagnosis of asthma, chronic/ recurrent cough or wheeze, exercise induced cough 
or breathlessness and with recurrent respiratory manifestations. Spirometry evaluates forced vital capacity (FVC), forced expiratory volume in first second $\left(F E V_{1}\right)$, the ratio of $F E V_{1}$ to $F V C$, peak expiratory flow rate (PEFR) and forced expiratory flow between $25 \%$ and $75 \%$ of vital capacity (FEF $25 \%$ \& $75 \%$ ). The base line spirometry, bronchodilator reversibility and histamine challenge are diagnostic of hyper-reactive airway with $98 \%$ sensitivity ${ }^{12}$. Spirometer is a computerized and self calibrating instrument that can asses respiratory functional parameters of a person in detail both in disease and normal status. To compare the lung function values of a diseased children, some reference values or nomogram is essential. Nomograms and regression equation for predicting lung function values in relation to height, weight, age and sex are present in different countries. We use the nomogram of lung function values of western and other countries. Recently, peak expiratory flow rate (PEFR) value of Bangladeshi children was determined by peak flow meter ${ }^{13}$. So far we know, there is no spirometric data of lung function values of Bangladeshi normal children. But it is proved by different studies that normal values of lung function tests differ from population to population in relation to race, socio-economic status and ethnic background. So for diagnosis, management, follow up and research on respiratory disorder it is important to have lung function values of normal children.

\section{Materials and Methods}

It was a cross sectional study conducted during February 2002 to July 2002. One school of Dhaka city was selected purposively for the study. Nine hundred twenty seven healthy children (M-463, F- 464) of class one to class ten were selected following the inclusion criteria (Boys and girls, 6-15 years of age, having no history of obvious chronic lung diseases, chronic cough, atopic diseases (asthma, eczema, rhino conjunctivitis), chest deformity, heart diseases or smoking habit). Proper clinical examination and information were recorded in a questionnaire by one of the authors. Age was calculated from the date of birth given by parents. Height was measured by stadiometer and weight was recorded by bathroom scale in children with school uniform and putting off shoes.

A computerized spirometer (Ponygraphic of COSMED srl-Italy) was used in this study. Before testing, the procedure was explained and demonstrated to each child. Each subject was allowed to practice at least three times and after being satisfied about the subject's ability to perform the test, three recordings were obtained and the best of the three was chosen for analysis.

All measurements were made in standing posture. FVC, FEV 1, FEV $_{1} /$ FVC\%, PEF and FEF ${ }_{(25 \%-75 \%)}$ were measured while the subject performed a forced vital capacity maneuver. Pulmonary function data were categorized on the basis of height, weight, age and body surface area but results have been produced on the basis of height as height showed maximum correlation in comparison with other variables as shown in different studies ${ }^{14-17}$.

Data analysis was done through SPSS win program. For significance chi-square and ' $\mathrm{t}$ ' test was done according to variables. The result (FVC) of present study was compared with results of other countries (India, Nigeria, British and America)

\section{Results}

The mean and standard deviation of the variables (FVC, $\mathrm{FEV}_{1}, \mathrm{FEV}_{1} / \mathrm{FVC} \%$, PEF and FEF $(25 \%-75 \%)$ were calculated at $10 \mathrm{~cm}$ interval against height 110-180 $\mathrm{cm}$ in male and $110-170 \mathrm{~cm}$ in female (Table-I and II). In figure 1 and 2 the mean values of $F V C$ and $\mathrm{FEV}_{1}$ are plotted against height. In both sexes the graph showed a fairly constant increase in FVC and $\mathrm{FEV}_{1}$ and sharper increase from height $150 \mathrm{~cm}$. Graphs of the other spirometric measurements follow approximately the same pattern but FVC and $\mathrm{FEV}_{1}$ is only shown in this article. Regression equation for prediction of lung function values $\left(\mathrm{FVC}, \mathrm{FEV}_{1}, \mathrm{FEV}_{1}\right.$ /FVC\%, PEF and FEF $(25 \%-75 \%)$ from independent variable (height) for boys and girls were performed (Table-III). In this study nomogram of FVC and FEV for boys and girls were constructed on the basis of regression equation (Table-III and Fig. 3 to 6), where height was considered as independent variable. The mean FVC value at two height levels $(120 \mathrm{~cm}$ and 160 $\mathrm{cm}$ ) of present study was compared with predicted mean from other study of different countries (India, Nigeria, America and Britain). The results of Nigeria, America and Britain were significantly higher than the mean FVC values of present study but the FVC of present result was almost similar to Indian study result (Table-IV). 
Table-I

FVC, FEV1, FEV1/FVC, PEF, FEF $25 \%-75 \%$ for studied male

\begin{tabular}{lccccc}
\hline Ht. $(\mathrm{cm})$ & $\begin{array}{c}\mathrm{FVC}(\mathrm{L}) \\
\text { Mean } \pm \mathrm{SD}\end{array}$ & $\begin{array}{c}\mathrm{FEV}_{1}(\mathrm{~L}) \\
\text { Mean } \pm \mathrm{SD}\end{array}$ & $\begin{array}{c}\mathrm{PEV}_{1} / \mathrm{FVC} \% \\
\text { Mean } \pm \mathrm{SD}\end{array}$ & $\begin{array}{c}\text { PEF } \\
\text { Mean } \pm \mathrm{SD}\end{array}$ & $\begin{array}{c}\mathrm{FEF}_{25 \%-75 \%} \\
\text { Mean } \pm \mathrm{SD}\end{array}$ \\
\hline $110-120$ & $0.99 \pm 0.12$ & $0.99 \pm 0.11$ & $99.82 \pm 0.17$ & $2.97 \pm 0.49$ & $2.04 \pm 0.49$ \\
$120-130$ & $1.26 \pm 0.19$ & $1.23 \pm 0.20$ & $98.21 \pm 0.48$ & $3.30 \pm 0.61$ & $2.13 \pm 0.50$ \\
$130-140$ & $1.59 \pm 0.25$ & $1.56 \pm 0.22$ & $98.61 \pm 0.27$ & $3.76 \pm 0.70$ & $2.60 \pm 0.51$ \\
$140-150$ & $1.99 \pm 0.32$ & $1.92 \pm 0.94$ & $96.59 \pm 0.49$ & $4.33 \pm 0.84$ & $2.90 \pm 0.56$ \\
$150-160$ & $2.64 \pm 0.32$ & $2.51 \pm 0.32$ & $95.25 \pm 0.51$ & $5.04 \pm 1.12$ & $3.43 \pm 0.69$ \\
$160-170$ & $3.09 \pm 0.35$ & $3.00 \pm 0.34$ & $97.17 \pm 0.39$ & $6.00 \pm 1.34$ & $4.33 \pm 0.89$ \\
$170-180$ & $3.53 \pm 0.37$ & $3.44 \pm 0.39$ & $97.54 \pm 0.95$ & $6.93 \pm 1.26$ & $4.97 \pm 0.89$ \\
\hline
\end{tabular}

Table-II

FVC, FEV1, FEV1/FVC, PEF, FEF $25 \%-75 \%$ for female

\begin{tabular}{lccccc}
\hline Ht. $(\mathrm{cm})$ & $\begin{array}{c}\mathrm{FVC}(\mathrm{L}) \\
\text { Mean } \pm \mathrm{SD}\end{array}$ & $\begin{array}{c}\mathrm{FEV}_{1}(\mathrm{~L}) \\
\text { Mean } \pm \mathrm{SD}\end{array}$ & $\begin{array}{c}\mathrm{PEV}_{1} / \mathrm{FVC} \% \\
\text { Mean } \pm \mathrm{SD}\end{array}$ & $\begin{array}{c}\text { PEF } \\
\text { Mean } \pm \mathrm{SD}\end{array}$ & $\begin{array}{c}\mathrm{FEF}_{25 \%-75 \%} \\
\text { Mean } \pm \mathrm{SD}\end{array}$ \\
\hline $110-120$ & $0.94 \pm 0.15$ & $0.93 \pm 0.15$ & $99.78 \pm 0.11$ & $2.61 \pm 0.58$ & $1.96 \pm 0.45$ \\
$120-130$ & $1.17 \pm 0.19$ & $1.15 \pm 0.19$ & $99.38 \pm 0.21$ & $2.99 \pm 0.61$ & $2.19 \pm 0.48$ \\
$130-140$ & $1.40 \pm 0.27$ & $1.39 \pm 0.26$ & $99.35 \pm 0.23$ & $3.50 \pm 0.83$ & $2.53 \pm 0.58$ \\
$140-150$ & $1.93 \pm 0.32$ & $1.87 \pm 0.30$ & $97.55 \pm 0.31$ & $3.67 \pm 0.96$ & $2.85 \pm 0.67$ \\
$150-160$ & $2.33 \pm 0.24$ & $2.28 \pm 0.23$ & $97.67 \pm 0.34$ & $4.31 \pm 1.11$ & $3.42 \pm 0.77$ \\
$160-170$ & $2.59 \pm 0.23$ & $2.54 \pm 0.18$ & $98.09 \pm 0.91$ & $5.06 \pm 1.17$ & $3.92 \pm 0.66$ \\
\hline
\end{tabular}

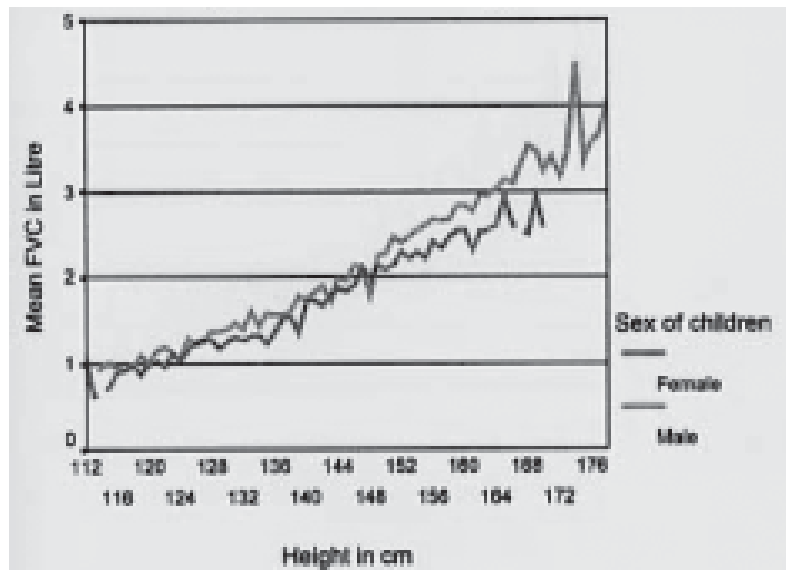

Fig-1: Mean FVC $(L)$ in relation to height and sex

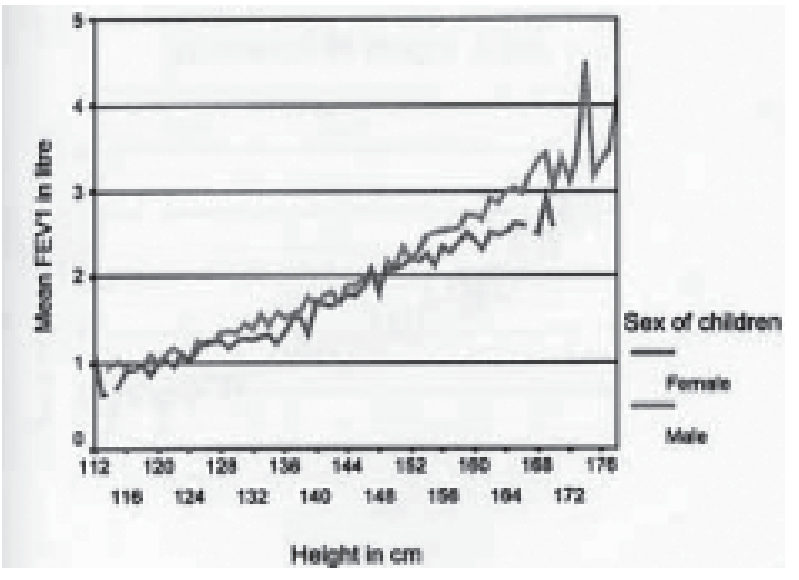

Fig-2: Mean FEV $1(L)$ in relation to height and sex 
Table-III

Regression equation for prediction of lung function values independent variable (height)

\begin{tabular}{|c|c|c|c|}
\hline \multirow[t]{2}{*}{$\overline{S e x}$} & \multicolumn{2}{|c|}{ Variables } & \multirow[t]{2}{*}{ Regression equation } \\
\hline & Dependent & Independent & \\
\hline Boys & FVC (L) & Height in $\mathrm{cm}$ & 0.047 x Ht. -4.77 \\
\hline Girls & $\mathrm{FVC}(\mathrm{L})$ & Height in cm & 0.038 x Ht. -3.73 \\
\hline Boys & FEV1 (L) & Height in cm & 0.045 x Ht.- 4.55 \\
\hline Girls & FEV1 (L) & Height in cm & 0.037 x Ht.- 3.55 \\
\hline Boys & FEV1 /FVC\% & Height in cm & 0.050 x Ht.+104.78 \\
\hline Girls & FEV1 /FVC\% & Height in cm & $0.057 \times$ Ht.+106.56 \\
\hline Boys & PEF (L/sec) & Height in cm & 0.067 x Ht.- 5.38 \\
\hline Girls & PEF (L/sec) & Height in cm & 0.045 x Ht.- 2.77 \\
\hline Boys & FEF 25\%-75\%(L/sec) & Height in cm & 0.052 x Ht.- 4.60 \\
\hline Girls & FEF 25\%-75\%(L/sec) & Height in cm & 0.040 x Ht.- 2.96 \\
\hline
\end{tabular}

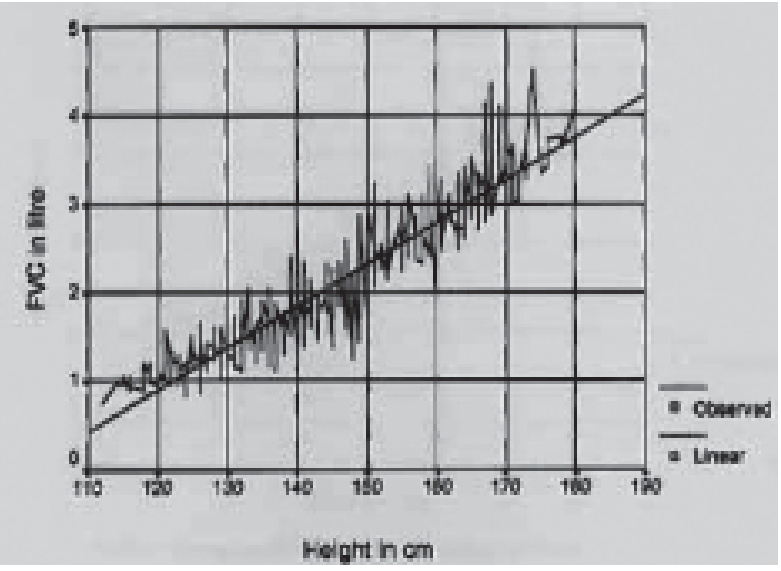

Fig-3: Nomogram of FVC (L) in boys in relation to Height

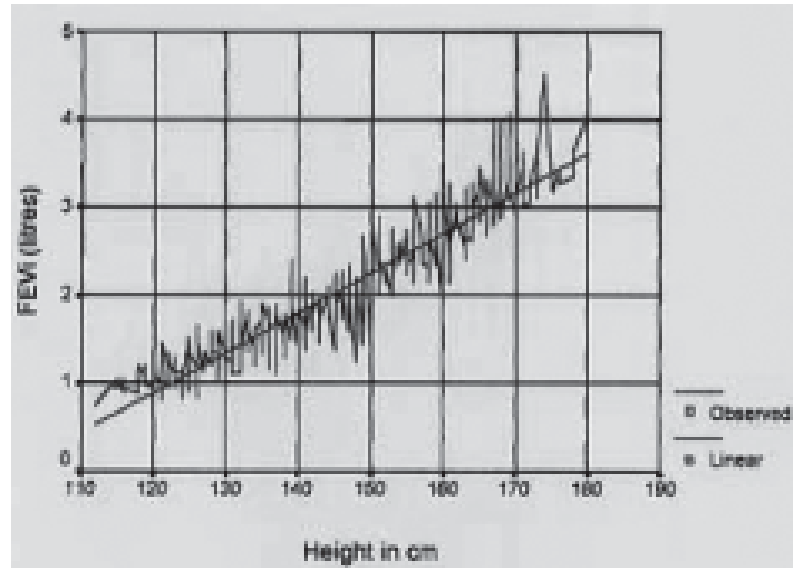

Fig-5: Nomogram of FEV ${ }_{1}(L)$ in boys in relation to Height

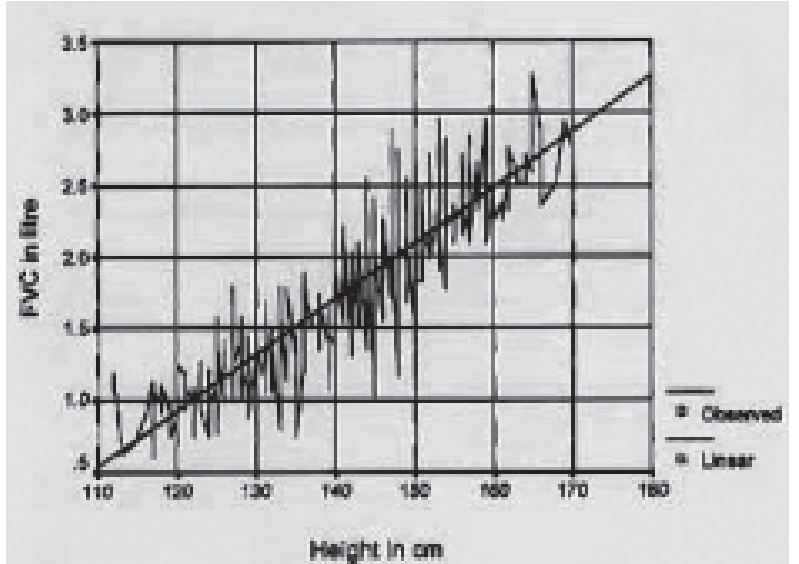

Fig-4: Nomogram of FVC (L) in girls in relation to Height

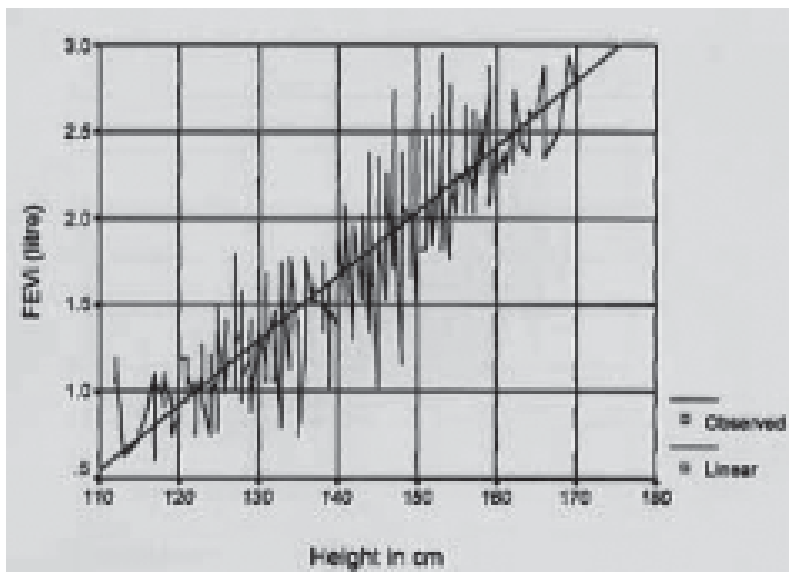

Fig-6: Nomogram of FEV $V_{1}(L)$ in girls in relation to Height 
Table-IV

Comparison of present result with other countries

\begin{tabular}{lcccccccc}
\hline Country & \multicolumn{3}{c}{ FVC (L) at Ht. of $120 \mathrm{~cm}}$. & \multicolumn{4}{c}{ FVC (L) at Ht. of $160 \mathrm{~cm}$} \\
& Male & P value & Female & P value & Male & P value & Female & P value \\
\hline Bangladesh & 1.26 & & 1.17 & & 3.09 & & 2.59 & \\
India & 1.42 & $<0.001$ & 1.22 & $>0.05$ & 2.63 & $<0.001$ & 2.64 & $>0.05$ \\
Nigeria & 1.66 & $<0.001$ & 1.59 & $<0.001$ & 3.27 & $<0.001$ & 3.35 & $<0.001$ \\
America (USA) & 1.52 & $<0.001$ & 1.40 & $<0.01$ & 3.54 & $<0.001$ & 3.24 & $<0.001$ \\
British (UK) & 1.49 & $<0.001$ & 1.46 & $<0.001$ & 3.89 & $<0.001$ & 3.42 & $<0.001$ \\
\hline
\end{tabular}

\section{Discussion}

This study determines the normal values of lung function and prediction formula in children. For the first time normal values and regression equation for healthy Bangladeshi children have been calculated. The positive correlation of lung function value with age, height, weight and body surface area observed in both sexes but most significant correlation observed with height, which was observed by other studies ${ }^{14-17}$. This study found the difference of mean values of lung function indices between boys and girls, which is significant in all height groups except $110-120 \mathrm{~cm}$ and $140-150 \mathrm{~cm}$. The lower values in girls were due to physiological reason and better performance of the boys. This may be due to anthropometric difference as well as factors such as difference in muscle strength and size and shape of the thoracic case between the sexes ${ }^{14}$. In this study we found rapid increase in pulmonary indices at approximately 150 $\mathrm{cm}$ onward which is comparable to other works ${ }^{18}$. FVC of present study result was compared with Indian, Nigerian, British and American results. The result (FVC) of present study is lower than Nigerian, British and American children. The difference with Indian results was not significant for girls but the results for boys was found significantly lower at $\mathrm{Ht}$. of $120 \mathrm{~cm}$ and higher at $\mathrm{Ht}$. of $160 \mathrm{~cm}^{14-18}$.

Lower values of FVC of present study correlates with a previous study of Bangladeshi adult male ${ }^{19}$. They found that lung capacities and volumes of our population were lower than those of Europeans by about $20 \%$. This study correlated with other study where they found difference in lung function in different ethnic groups ${ }^{20}$. In this study the nomogram was constructed from height based regression equation.

This small study in an urban school does not reflect the whole country status. So, we need to do large study.

\section{Acknowledgements}

We wish to acknowledge the cooperation and help extended by the students, parents, teachers and school administration of Udayan Uchah Maddaymic Biddalayh, Dhaka. We are greatfull to Dr. Mujadded Ahmed, Asstt. Professor (Epidemiology), Institute of Health Technology, Dhaka, for taking all the pain to do the data analysis to bring a comprehensive results.

\section{References}

1. Kabir ARML, Hasan MR, Rahman F, Amin MR. Mahamud ASM, Hasan MA, Bennor KS, Rahman MN. Prevalence of reported Asthma symptom in children of Bangladesh. Bangladesh J children health 2002; 26: 3-8.

2. Andrew H Liu, Joseph D Spahn, Donald YM Leung. Childhood Asthma. In: Behrman RE, Kliegman RM, editors. Nelson Textbook of Pediatrics. $17^{\text {th }}$ ed. Philadelphia: WB Saunders Company; 2004. P. 760-74 .

3. Kabir ARML, Rahman F, Hasan Q, Ahmed F, Mridha MA, et al. Asthma, atopic eczema and allergic rhino conjunctivitis in school-age children of Dhaka, Bangladesh using ISAAC protocol. Mymensingh Med J 2005; 14: 3-5.

4. Kabir ARML, Rhaman F, Mannan MA, Chanda SK, Chaowdhury AT. Prevalence of wheeze and asthma in children of a coastal community of Bangladesh. Bangladesh J Child Health 1999; 23: 43-47.

5. Hasan MR, Kabir ARML, Mahmud AM, Rhaman F, Hossain MA, Bennor KS et al. Self reported asthma symptoms in children and adults of Bangladesh; Findings of the National Asthma Prevalence. International Study of Epidemiology 2002; 31: 483-88. 
6. Shamssain $\mathrm{MH}$, Shamsain N. Prevalence and severity of asthma, rhinitis and atopic eczema: the north east study. Arch Dis child 1999; 81: 313-17.

7. Austin JB, Russell G. Wheeze, cough, atopy and indoor environment in the scotish Highlands. Arch Dis Child 1997; 76: 22-26.

8. The international study of asthma and allergies in childhood (ISAAC) steering committee. Worldwide variation in prevalence of symptoms of asthma allergic rhinnocojunctivitis and atopic eezema: ISAAC. Lancet 1995; 351: 1225-32.

9. Austin JB, Kaur B, Anderson HR, Burr M, Harkins LS, Strachan DP et al. Hay fever eczema and wheeze: a nation wide UK study (ISAAC, International study of asthma \& allergies in childhood). Arch Dis child 1999; 81: 226-30.

10. Lebowitz MD. The use of peak expiratory flow rate measurements in respiratory disease. Pediatr pulmonol 1991; 11: 166-74.

11. Swarminathan S. Pulmonary function testing in office practice. Indian J Pediatr 1999; 66: 90415.

12. Amdekar YK, Ugra D. Pulmonary function tests. Indian J Pediatr 1996; 63: 149-52.

13. Mridha MAA, Amin MR. Peak expiratory flow rate (PEFR) in normal school children of Dhaka city, Bangladesh. Bangladesh J Child Health 2002; 26: 46-51.

14. Olanrewaju DM. Spirometric standards for healthy Nigerian children and adolescents. East Afr Med J 1991; 68: 812-19.

15. Dickman LM, Schmidt CD, Gardnar MR. Spirometric standards for normal children and adolescents (ages 5 years through 18 years). American Review of Respiratory Disease 1971; 104: 680-87.

16. Godfrey S. Kamburof PL, Nairn JR. Spirometry, lung volumes and airways resistances in normal children aged 5-18 years. Br J Dis Chest 1970; 64: $15-24$

17. Malik SK, Jindal SK. Pulmonary function test in healthy children. Indian Pediatric 1985; 22: 7680.

18. Chowgule RV, Shetye VM, Parmar JR. Lung function test in normal Indian children. Indian Pediatrics 1995; 32:185-91.

19. Choudhury S, Alam SM, Begum NQ. Lung function parameters of Bangladeshi male subjects in different living condition. Bangladesh Med Res Counc Bull 1997; 23: 30-33.

20. Roizin H, Szeinberg A, Tabachinik E. Ethnic differences in lung function in Israeli children. Thorax 1993; 48: 906-10. 